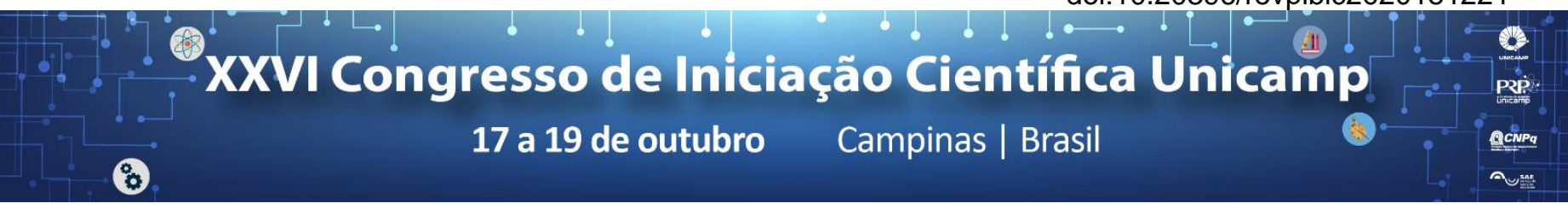

\title{
Aproveitamento Energético e o Desenvolvimento de Metodologia para Inventário de Palha de Cana de Açúcar na Região Administrativa de Campinas.
}

\section{Rodrigo F. Vieira*, Mauro D. Berni.}

\begin{abstract}
Resumo
Atualmente, países buscam alcançar uma sociedade de consumo que seja mais sustentável. Um exemplo disto está na energia elétrica que pode ser gerada a partir de resíduos agrícolas. Neste contexto, o Brasil apresenta destaque uma vez que possui grande extensão de sua área ocupada por culturas agrícolas que geram resíduos produzidos durante as suas colheitas. Este projeto tem como objetivo inventariar e avaliar o potencial energético e a disponibilidade de resíduos agrícolas da cana de açúcar, na Região Administrativa de Campinas (RAC). Para tanto, adota-se uma metodologia que contempla o potencial técnico de geração elétrica da palha de cana de açúcar, mediante equações matemáticas com base em indicador da produção de resíduos agropecuários. Utiliza-se o software ArcGis na análise espacial para identificação das áreas com esses resíduos, sendo input para estimar a quantidade que poderá ser utilizada para geração de energia elétrica.
\end{abstract}

Palavras-chave:

ArcGis, Cana de Açúcar, Bioeletricidade.

\section{Introdução}

O aproveitamento de resíduos agrícolas é o cerne da transição para uma economia de baixo carbono. Os resíduos da cultura de cana de açúcar têm um papel fundamental a desempenhar na mitigação e na adaptação, não só devido ao seu papel de sorvedouro de $\mathrm{CO}_{2}$, mas também ao potencial de geração de bioeletricidade como alternativa a outras fontes fósseis de geração de energia elétrica. No caso dos resíduos da cana de açúcar, compostos por folhas secas e ponteiras, o principal uso até o momento é na cogeração em associação ao bagaço. Todavia, ainda muito aquém do potencial técnico disponível (Franco et al., 2013).

Neste contexto, o objetivo deste projeto foi o de inventariar a produção de palha de cana de açúcar e sua localização geográfica com o auxílio do software ArcGis na Região Administrativa de Campinas (RAC). Por fim, é avaliada a capacidade da produção de bioeletricidade, tendo em vista atender a demanda por energia elétrica na RAC.

\section{Resultados e Discussão}

A fase inicial do projeto teve como pré-requisito a elaboração de um inventário em termos do tamanho das áreas de cultivo e geração de resíduos de cana de açúcar na RAC, utilizando-se uma metodologia baseada no conceito de clusters. A partir dos dados levantados e de informações obtidas na literatura foi possível determinar a quantidade de palha gerada na RAC. Para a determinação do potencial energético da palha calculouse 0 seu poder calorífico inferior a partir de sua composição química e de equações obtidas na literatura (Nogués et al., 2010). O resultado obtido é apresentado na Tabela 1.

Com estes dados e informações foi possível determinar o potencial de geração de energia elétrica (PGE) da palha (Tabela 1). Para a avaliação deste resultado levantou-se o consumo de energia elétrica na RAC no ano de 2017. As análises do consumo foram realizadas de forma comparativa as demandas de diferentes setores, como residencial, rural, industrial, comercial e público.
Tabela 1. Resultados obtidos.

\begin{tabular}{|l|c|}
\hline Resíduos gerados na RAC & $2.016 .793,17[\mathrm{t}]$ \\
\hline Poder Calorífico Inferior da palha & $3982,3[\mathrm{Mcal} / \mathrm{t}]$ \\
\hline PGE da palha & $9.332 .574 .462[\mathrm{kWh}]$ \\
\hline Consumo de EE na RAC (2017) & $25.641 .052 .036[\mathrm{kWh}]$ \\
\hline
\end{tabular}

A partir dos resultados da Tabela 1, verificou-se que com aproximadamente $91 \%$ do total de energia elétrica gerada a partir da palha, não pode-se atender somente o consumo total dos setores comercial e industrial da RAC. Esta oferta significa atender 33,2\% do consumo de energia elétrica da RAC no ano de 2017.

Analisando-se economicamente o contexto, tem-se que o custo médio de uma usina hidrelétrica (UHE) no Brasil corresponde a $2.648 \mathrm{R} \$ / \mathrm{kW}$ instalado (CPFL; GESEL, 2015). Assim, a quantidade de energia elétrica que pode ser utilizada na RAC gerada a partir da palha de cana de açúcar resultaria em uma economia de 2,6 bilhões de reais por ano. Com esta economia evitada tem-se a alternativa de investimentos em geração descentraliza próxima aos pontos de consumo, a partir da palha.

\section{Conclusões}

Além da economia nos custos da implantação de novas UHE distantes de centros consumidores, tem-se os custos evitados com novas linhas de transmissão para atender a demanda crescente, mitigação de impactos ambientais das grandes barragens e produção de gases de efeito estufa.

\section{Agradecimentos}

Ao CNPq e à PRP-UNICAMP, Programa PIBIC pela bolsa de auxílio, ao NIPE pela estrutura e suporte material, ao doutorando Christy W. S. Romero pela ajuda no uso do software de georreferenciamento ArcGis.

$\overline{{ }^{1} F r a n c o, ~ H . ~ C . ~ J . ; ~ P i m e n t a, ~ M . ~ T . ~ B . ; ~ C a r v a l h o, ~ J . ~ L . ~ N . ; ~ M a g a l h a ̃ e s, ~ P . ~ S . ~ G . ; ~}$ Rossell, C. E. V.; Braunbeck, O. A.; Vitti, A. C.; Kölln, O. T. e Neto, J. R. Assessment of Sugarcane Trash for Agronomic and Energy Purposes in Brazil. 2013.

2 Nogués, F. S.; Galindo, D. G. e Rezeau, A. Energía de la biomassa 1. ed. Zaragoza: Prensas Universitarias de Zaragoza, 2010.

${ }^{3}$ CPFL; GESEL. Panorama e análise comparativa da tarifa de energia elétrica do brasil com tarifas praticadas em países selecionados, considerando a influência do modelo institucional vigente, 2015 